\title{
Policy matrix for sustainable soil management and climate-resilient agriculture
}

\author{
P. Dey
}

Land governance, extension and advisory services, finance and market, local governance and cooperation models, together with monitoring and evaluation at all stages are important for the development of policy matrix towards sustainable land management (SLM) and climate-resilient agriculture. Addressing tenure insecurity at intra-household level by giving women access to landuse rights, legal recognition and protection of land tenure, involving different stakeholders in policy-making processes, and integration of SLM into community development plans are pivotal for development of the policy. In addition, adoption of ICT, incorporating externalities for making economic decisions, accounting for capital invested in the face of climate change, strengthening local and community governance structures, and development of voluntary guidelines on SLM in sync with local law are essential elements for the development of such a policy.

Keywords: Climate-resilient agriculture, policy matrix, soil health, sustainable land management.

To capture the evidence of positive impacts to soil, environment and livelihood, a policy matrix was synthesized by extracting useful insights from success stories and case studies, mainly from Africa and a few from Asia, for the formulation of broader development strategies and policy recommendations for achieving sustainable land management (SLM) and climate-resilient agriculture. The four dimensions of land governance, extension and advisory services, finance and market, local governance and cooperation models, together with monitoring and evaluation at all stages are important for creating an enabling environment for sustainable and climate-resilient agriculture. Adoption of ambitious global targets on sustainable development and climate action does not provide answers regarding how to achieve these goals, especially related to environment and soil, i.e., SDG 13 and SDG 15 goals on the ground. The adaptive management approaches that allow alignment with local realities are key to successful implementation of the sustainable development goals (SDGs) on the ground.

\section{Land governance}

Experiences of success stories from Burkina Faso and Kenya in Africa showed that addressing tenure insecurity at intra-household level and giving women access to land-use rights which encouraged men to support women's land ownership and convinced authorities at the local

P. Dey is in the ICAR-Indian Institute of Soil Science, Nabibagh, Berasia Road, Bhopal 462 038, India.

e-mail: pradipdey@yahoo.com body to lend support, was found useful to take decisions at their own space. Women's access to resources is largely determined at the local level. The objective of these negotiations was to change existing tenure arrangements towards enhanced equality and security for women. Changing traditional tenure arrangements towards more equitable access to land therefore, needs locally led and culturally sensitive processes. Governance and development are intertwined, and there exists a strong positive association between governance indicator and development outcome ${ }^{1,2}$. Upscaling of SLM at the local level faced a major bottleneck due to lack of women's access to and control over land, despite the major contributions they make to food security and household income. Ecosystem-based adaptation through coordinating and engaging key stakeholders and actors stimulates positive results in SLM.

\section{Extension and advisory services}

Involving different stakeholders in policy-making processes is important for mainstreaming of successful SLM practices into policies. The broad clusters of strategies relating to an enabling environment are: identifying the first-line champion from the farmers to sustain SLM technologies, building capacities of such champions to equip them with soft skills, strengthening and building capacities of local institutions and developing strong linkages between researchers and farmers. The future of extension lies with: the scalability of technologies, digital platforms, diversification of its purpose and profiling its case to the political level. Ensuring budget allocation is 
possible through integration of SLM into communitydevelopment plans and adoption of ICT (information and communications technology) by different actors. There is an urgent need for mainstreaming of rational traditional SLM practices in development policies and programmes, as well as for raising the profile of extension services at the political level.

Engaging civil society organizations (CSOs) in land tenure agreements, involving partners at different stages of planning process, supporting appropriate legal mechanisms, creating a platform to bring together local and communal legal entities for effective and meaningful consultation, developing inclusive platforms to operationalize actions; and building capacity to monitor and document the success stories as evidence to further inform policy making at national and regional levels are few strategies for success. Cross-country regression analysis of 40 nations showed that trust was higher in countries with less income inequality and a more reliable legal mechanism $^{3}$.

\section{Finance and market}

Financial institution and refinancing can be a game changer in the market with its focus on catalysing the private sector to direct resources to scale up SLM practices through creating a pipeline of bankable projects. Finance and market require a paradigm shift to incorporate externalities for making economic decisions, and account for capital invested in the face of climate change. Creating an enabling environment by providing opportunities for refinancing and provision of loans to farmers along with microfinancing programmes, especially for women, and handholding to establish farmer-producer organizations are the need of hour. Building trust is also important for finance, as low trust environment reduces investment ${ }^{4}$. Steps like incorporating external costs, inclusive carbon markets, offering incentives for smallholders to invest in SLM, and accounting for benefits of biodiversity into economic and financial decision-making are also warranted. Limited financing for the SDGs requires achieving multiple benefits for investment, linking SLM actions to other goals at the local level.

\section{Local governance and cooperation models}

Strategies should focus on strengthening local and community governance structures which underpins all other strategies related to supporting access to land for women, secure extension services as well as access to markets and finance. Trust and civic cooperation was found to have significant impact on development ${ }^{5}$. Although there are challenges in linking statutory and customary governance, we need to find complementarities rather than competing against each other together with increased col- laboration among different service providers and local governments as a platform for dialogue. Also, international legal frameworks can support rights-based approaches to SLM at the local level. Another strategy could be development of voluntary guidelines on SLM in sync with local law through stakeholder consultation and implementation through pre-eminent NGOs. On integrating local regulatory initiatives into policy, legal and institutional frameworks, inter alia, for increased advocacy and awareness raising, capacity building at institutional and individual levels, and multi-stakeholder platforms are essential to ensure the full and meaningful participation of all stakeholders.

Experiences from Benin, Africa, showed the importance of community mobilization for land sustainability. In this case, municipality was used successfully as an intermediary for the transfer of technology. It was concluded that for successful implementation and sustainability, benefits need to be equitably shared in the project area. It was observed that strong involvement of actors responsible for implementing rural development initiatives, such as public agricultural extension institutions and the district administration, is key to bringing these initiatives to scale. For example, by means of their active participation throughout the process, the district administration acquired the necessary institutional knowledge to replicate this process in other villages. Also to retain youth in agriculture, there is an urgent need to include different practices, such as hydroponics.

The importance of effective packaging of local governance initiatives and involving civil society networks to translate these messages to influence decision makers at higher levels; lobbying relevant stakeholders to ensure that community guidelines are not only incorporated in policy but are also, wherever possible, enshrined into law, and conducting awareness campaigns are some of the check points to ensure the implementation of such guidelines. The proposed strategies must be reformulated wherever necessary, to address and operationalize at the local, sub-national and national levels. Issues regarding the common property management vis-à-vis land degradation need to be addressed adequately. This is important in the Indian context, wherein the livelihoods of tribal and small and marginal farmers are dependent on commons, i.e. natural resources accessible to all members of a society; role and engagement in governance and management of soil degradation issues in commons, will be critical.

\section{Conclusion}

Women's land rights are a prerequisite to achieving SLM. Efforts to develop locally led tenure frameworks to guarantee women's access to and ownership of land from the household and community level to ensure legitimacy; 
amplifying advocacy by linking with civil society organizations, and ensuring that such local agreements are formally recognized at the sub-national and national levels. There is an urgent need to create responsible rural governance besides strengthening of microfinance and other institutions for channelizing capital flow to farmers/other community groups.

Common advocacy platforms and interaction between parties to exchange ideas are central to advance healthy land and agricultural activities. Traditional practices along with revival in the traditional decision-making systems to manage natural resources, especially in dryland areas, were found to provide positive results. An important condition for the success of community-led landlease guidelines through community dialogue with close involvement of village and community leaders as well as local authorities, rather than being imposed from the outside, enhanced the legitimacy and eased adoption within the community and legal system. The above discussion clearly demonstrates that opportunities do exist to create an enabling environment for sustainable and climateresilient agriculture vis-à-vis maintenance of soil health.

The core policy should revolve around enabling global solutions at the local level in sync with good rural

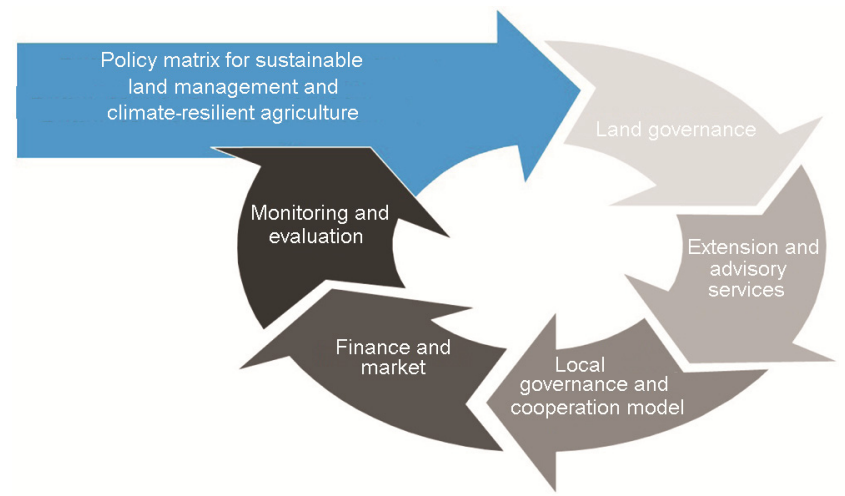

Figure 1. Key matrix for sustainable land management and climate resilient agriculture. governance incorporating all broad ingredients (Figure 1). There is an urgent need for commitment to support and engage marginalized populations in SLM, emphasizing the need to scale-up successful case studies and further improve technical and functional capacity-building. Also, there is an urgent need to translate scientific evidence into action for finding solutions to the paradox of growing hunger in some parts of the world while there is significant food waste in other parts. The legal recognition and protection of communal land tenure, land use and land management rights for pastoral communities, developing increased political will through advocacy and lobbying are few other issues that need attention. The Indian soil policy is also long-awaited; hopefully, the above check points will also serve as pillars to develop a robust workable policy.

1. Reynolds, L. G., The spread of economic growth to the Third World: 1850-1980, J. Econ. Lit., 1983, 21, 941-980.

2. Kaufmann, D., Kraay, A. and Zoido-Lobatàn, P., Governance matters. Policy Research Working Paper No. 2196, The World Bank Development Research Group Macroeconomics and Growth and World Bank Institute Governance, Regulation, and Finance, 1999.

3. Zak, P. J. and Knack, S., Trust and growth. IRIS Centre Working Paper No. 219, University of Maryland, College Park, MD, USA, 1998.

4. Zak, P. J. and Knack, S., Trust and growth. Econ. J., 2001, 111, $295-321$.

5. Knack, S. and Keefer, P., Does social capital have an economic payoff? A cross-country investigation. Q. J. Econ., 1997, 112, $1251-1288$.

ACKNOWLEDGEMENTS. I thank ICAR for timely approval of deputation, Deutsche Gesellschaft für Internationale Zusammenarbeit for funding the visit, and Töpfer, Müller, Gaßner - Think Tank for Sustainability (TMG Research), Germany for facilitating discussions and providing useful insights during the Global Soil Week-2019 during 2630 May at ICRAF, Nairobi, Kenya.

Received and accepted 6 July 2019

doi: $10.18520 / \mathrm{cs} / \mathrm{v} 118 / \mathrm{i} 2 / 199-201$ 